\title{
Syncope and Ictal Asystole Caused by Temporal Lobe Epilepsy
}

\author{
Ritsuko Kohno, MD; Haruhiko Abe, MD; Naoki Akamatsu, MD; Yasushi Oginosawa, MD; \\ Masahito Tamura, MD; Masaaki Takeuchi, MD; Yutaka Otsuji, MD
}

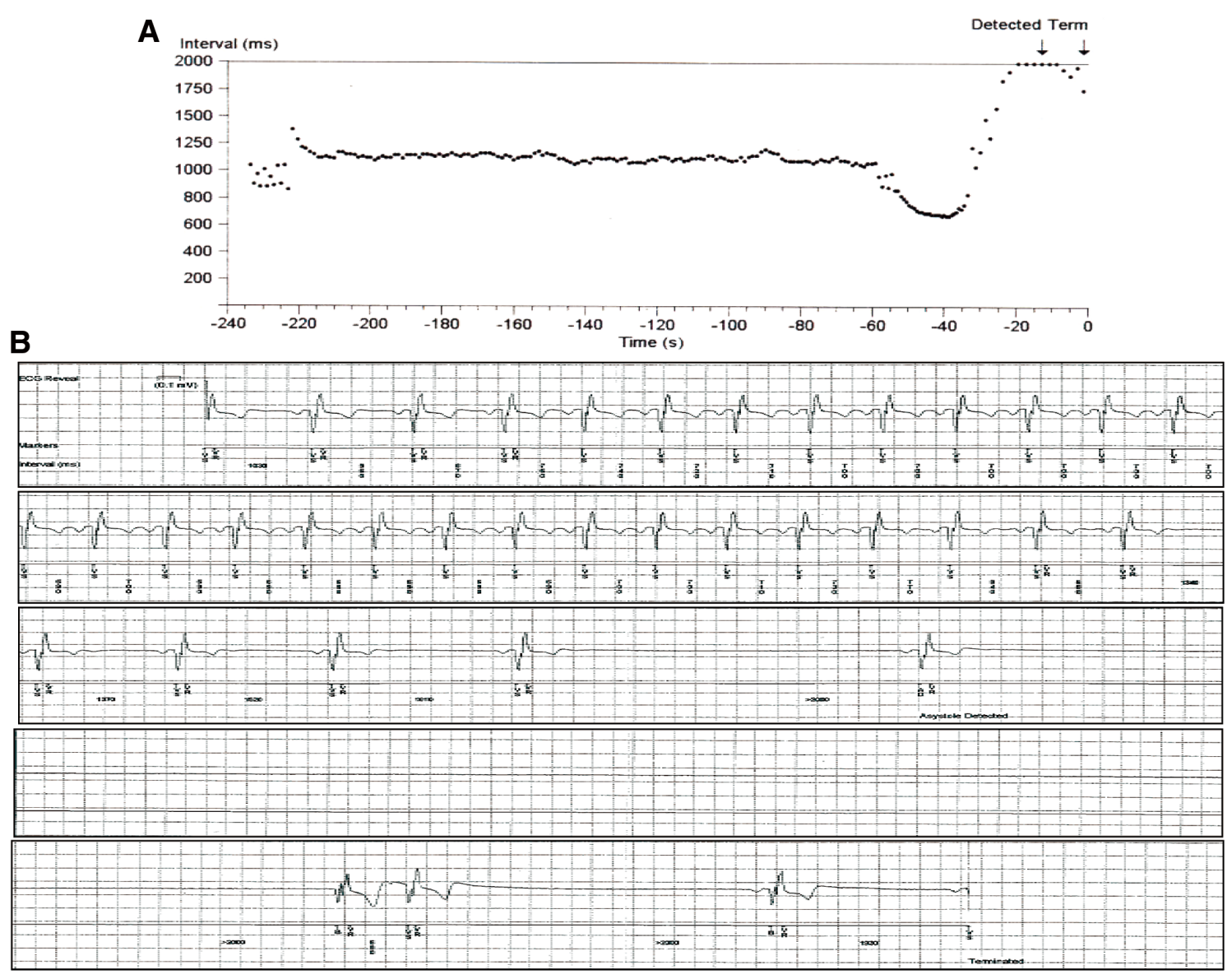

Figure 1. (A) Heart rate trend during an auto-activated event recorded by the implantable loop recorder. (B) Electrocardiogram showing a transient increase in heart rate followed by a gradual decrease, culminating in 18-s asystole.

$\mathbf{S}$ yncope is defined as loss of consciousness and postural tone due to transient global cerebral hypoperfusion. Although it may also manifest as transient loss of consciousness, epilepsy is not due to cerebral hypoperfusion, and its treatment differs markedly from that of syncope. ${ }^{1}$
A 66-year-old, right-handed man presented with a 1/2-year history of 2 to 3 episodes of syncope/month, usually preceded by epigastric discomfort and followed by feelings of warmth, diaphoresis and nausea. The frequency and severity of his syncopal attacks gradually increased over time, some eventu-

Received March 8, 2011; revised manuscript received May 19, 2011; accepted June 1, 2011; released online July 12, 2011 Time for primary review: 8 days

Second Department of Internal Medicine (R.K., Y.Oginosawa, M. Tamura, M. Takeuchi, Y. Otsuji), Department of Heart Rhythm Management (H.A.), Department of Neurology (N.A.), University of Occupational and Environmental Health, Kitakyushu, Japan

Mailing address: Haruhiko Abe, MD, PhD, Department of Heart Rhythm Management, University of Occupational and Environmental Health, 1-1 Iseigaoka, Yahatanishi-ku, Kitakyushu 807-8555, Japan. E-mail: haru-abe@med.uoeh-u.ac.jp

ISSN-1346-9843 doi:10.1253/circj.CJ-11-0261

All rights are reserved to the Japanese Circulation Society. For permissions, please e-mail: cj@j-circ.or.jp 


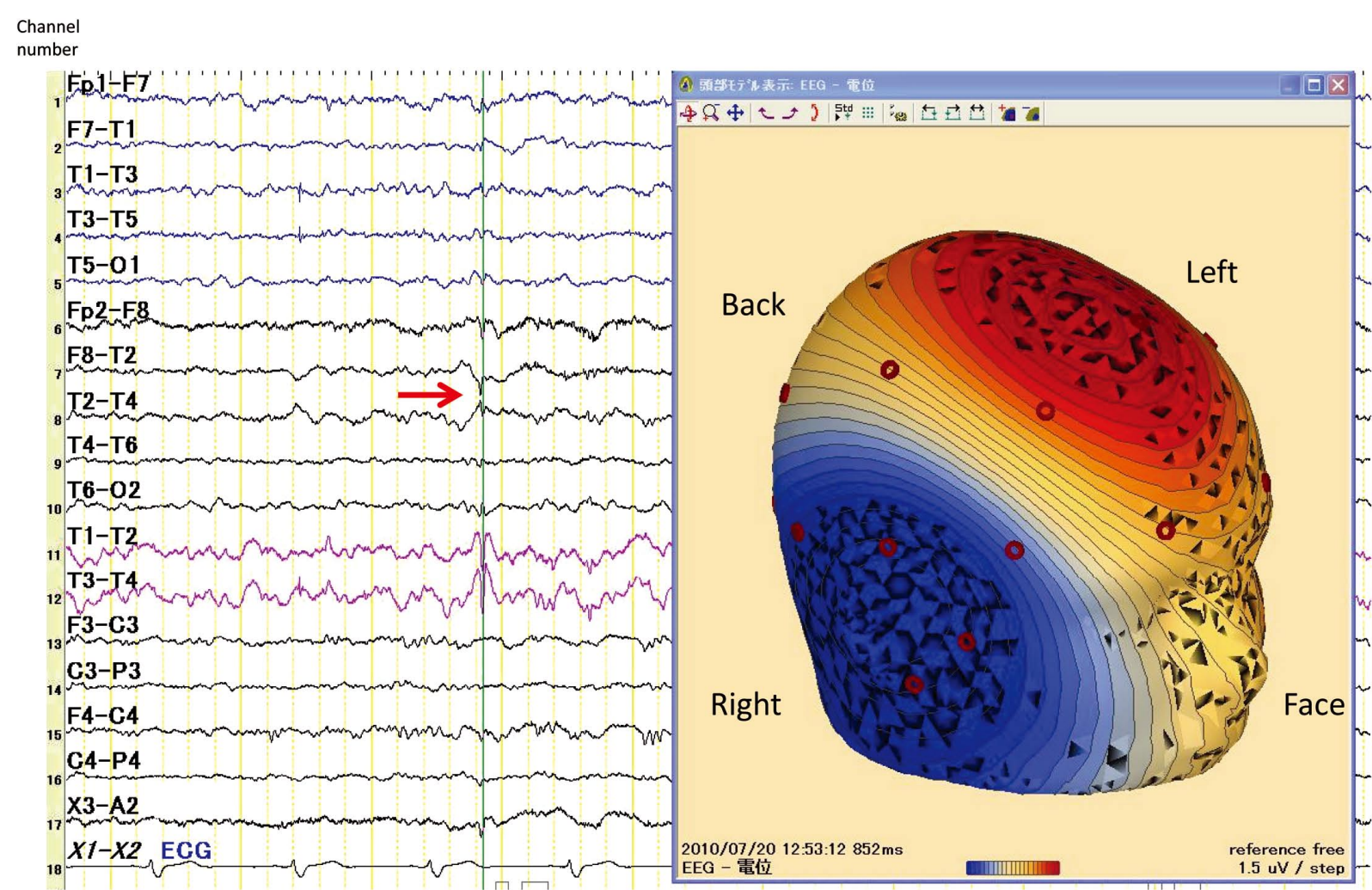

Figure 2. Interictal electroencephalogram (ECG) and scalp topographical mapping. Green vertical line, point of the right temporal spike. The interictal spike shows phase-reversal at the T2 electrode (between channels 7 and 8 ). Red arrow, phase-reversal point and typical epileptiform discharge. The phase-reversal point is that at which epileptispike polarity is reversed on bipolar montage. The phase-reversal point indicates epileptogenic area. Blue area on the head model, negative electrical field on the scalp (right side of the head). Red area, positivity (left side of the head). This indicates that the interictal spike arises from the right temporal lobe. Channels $1-5,6-10,11,12$, and 13-17 on the left side of electroencephalogram (EEG) represent left temporal chain with bipolar derivation (blue EEG in top tracing); right temporal chain (black EEG in middle tracing); right and left temporal long distance derivation (purple EEG in middle tracing); and parasagittal derivation (black EEG in bottom tracing), respectively.

ally resulting in traumatic injury. His wife observed that he briefly became pale and unresponsive during these times, in the absence of automatic or tonic-clonic movements, and promptly regained consciousness thereafter. He had no family history of epilepsy. General physical and neurologic examinations, including orthostatic vital signs, and computed tomography of the head, were normal. A 12-lead electrocardiogram (ECG) showed sinus rhythm at a rate of 72 beats/min, complete right bundle branch block and left posterior fascicular block. Cardiac investigations including transthoracic echocardiography, ambulatory ECG monitoring, chest radiography, and treadmill exercise testing were all normal. A head-up tilt test at $80^{\circ}$ for $30 \mathrm{~min}$ was negative. Because the patient had recurrent unexplained syncope in presence of an abnormal ECG, he underwent implantation, in accordance with the guidelines issued by the European Society of Cardiology, ${ }^{1}$ of a Reveal ${ }^{\circledR}$ DX 9528 loop recorder (ILR; Medtronic, Minneapolis, MN, USA).

The patient experienced 3 syncopal episodes during the 3 months following ILR implantation. The ECG during syncope monitored with ILR showed first an increase, then a gradual decrease in heart rate, ending with sinus bradycardia at a rate of 30-40 beats/min for $10 \mathrm{~s}$. In addition, 27 nocturnal, asymptomatic events were recorded automatically. All record- ings showed first an increase, then a gradual decrease in heart rate, ending with profound bradycardia or asystole lasting up to $18 \mathrm{~s}$ (Figure 1). A sleep disorder was excluded on normal polysomnography. The patient then underwent a 16-channel electroencephalogram (EEG), using the 10-20 international system, which showed interictal epileptiform discharges over both anterior temporal regions (Figure 2). The patient was diagnosed with temporal lobe epilepsy (TLE), associated with ictal bradycardia and asystole. His symptoms disappeared after initiation of oral carbamazepine at $100 \mathrm{mg}$ daily, although the ILR continued to record asymptomatic nocturnal bradycardia and asystole. After the carbamazepine was increased to $200 \mathrm{mg} /$ day, no further episodes of bradycardia or asystole were recorded and no recurrence of syncope was observed during 9 months of follow-up.

Although epilepsy and reflex syncope can both cause a transient loss of consciousness and, on occasion, share prodromes, the pathophysiological mechanisms underlying these 2 clinical entities are very different. Syncope is caused by transient global cerebral hypoperfusion, while epilepsy is caused by abnormal electrical activity of the brain without global cerebral hypoperfusion. Marked fluctuations in heart rate, well-documented in patients with reflex syncope, may also occur in patients with seizure disorders, with ictal 
bradycardia, asystole or both observed in up to $0.27 \%$ of all patients with epilepsy. ${ }^{2}$ In addition, typical signs of TLE, such as motionless staring, automatic movements of the hands or mouth, communication disorders, abnormal speech or behavior, are not always present and were not observed in the present patient, blurring the distinction between syncope and TLE.

ILR are used in the investigations of unexplained syncope, and may also help diagnose generalized tonic-clonic seizures as a cause of recurrent, unexplained episodes of loss of consciousness. Myopotential noise during convulsion have been clearly demonstrated using ILR in patients with generalized tonic-clonic seizure in previous reports. ${ }^{3,4}$ In the present case, ictal asystole, without myopotential noise, was demonstrated with ILR as a complex partial seizure of typical TLE. Furthermore, bradyarrhythmias requiring permanent pacing were documented in $20 \%$ of epileptic patients monitored with an ILR, ${ }^{5}$ suggesting a relationship with the syndrome of sudden unexpected death, which affects approximately 7-17\% of the epileptic population, ${ }^{6}$ or an estimated $0.12 \%$ of epilepsy patients per year. ${ }^{5}$

The contribution of cardiac pacing in the therapy of ictal bradycardia/asystole associated with TLE remains controversial. $^{7-11}$ Earlier studies have found permanent pacing effective $^{7-9}$ or ineffective. ${ }^{10,11}$ Schuele et al reported similar changes in heart rate and duration of asystole during clinical events in patients presenting with ictal bradycardia/asystole versus neurally mediated reflex syncope, suggesting that both are mediated by a mechanism involving medullary reflex centers and a transient increase in vagal tone. ${ }^{2}$ In multicenter randomized studies, permanent pacing was ineffective in patients presenting with neurally mediated reflex syncope. ${ }^{12,13}$ Therefore, it may also be ineffective in patients with syncope induced by ictal bradycardia/asystole. The present patient was treated with carbamazepine alone and remained free from syncope and ictal bradycardia/asystole during 9 months of follow-up. After the dose of carbamazepine was increased to $200 \mathrm{mg} / \mathrm{day}$, neither syncope nor the nocturnal asystole was confirmed. In addition, interictal EEG spikes had disappeared. In daily clinical practice, most patients with TLE are usually confirmed to have interictal EEG spikes without the clinical seizure. Although we could not record EEG simultaneously during the asystole, a history suggesting temporal lobe seizure and the presence of interictal spikes strongly indicated a diagnosis of TLE. Furthermore, the complete abolishment of asystole by the anti-epileptic medication (carbamazepine) further confirmed that asystole was caused by the seizure activities.
In conclusion, TLE, typically manifesting as complex partial seizure without convulsions, may be associated with ictal bradycardia/asystole, and may not be detected as the cause of syncope. ILR is a reliable means of diagnosing ictal bradyarrhythmias, which may be similar to those observed in patients with neurally mediated reflex syncope, ${ }^{14,15}$ even asymptomatic. Anti-epileptic drug therapy is likely to be effective in epilepsy patients presenting with syncope.

\section{References}

1. Moya A, Sutton R, Ammirati F, Blanc JJ, Brignole M, Dahm JB, et al. Guidelines for the diagnosis and management of syncope (version 2009). Eur Heart J 2009; 30: 2631 - 2671.

2. Schuele SU, Bermeo AC, Locatelli E, Burgess RC, Lüders HO. Ictal asystole: A benign condition? Epilepsia 2008; 49: 168-171.

3. Ho RT, Wicks T, Wyeth D, Nei M. Generalized tonic-clonic seizures detected by implantable loop recorder devices: Diagnosing more than cardiac arrhythmias. Heart Rhythm 2006; 3: 857-861.

4. Betsuyaku T, Sato M, Sugiyama E, Muto H, Minoshima A, Tamada A, et al. A case of loss of consciousness due to epilepsy diagnosed using an implantable loop recorder. J Arrhythmia 2011; 27: 76-79.

5. Rugg-Gunn FJ, Simister RJ, Squirrell M, Holdright DR, Duncan JS. Cardiac arrhythmias in focal epilepsy: A prospective long-term study. Lancet 2004; 364: 2212-2219.

6. Sperling MR. Sudden unexplained death in epilepsy. Epilepsy Curr 2001; 1: $21-23$

7. Dinan A, de Toffol B, Pallix M, Breard G, Babuty D. Cardiac arrest: It's all in the head. Lancet 2008; 371: 1476.

8. Carvalho KS, Salanova V, Markand ON. Cardiac asystole during a temporal lobe seizure. Seizure 2004; 13: 595-599.

9. Almansori M, Ijaz M, Ahmed SN. Cerebral arrhythmia influencing cardiac rhythm: A case of ictal bradycardia. Seizure 2006; 15: 459461.

10. Kasim S, Hennessy M, Crowley J. Persistent fainting after implantation of a "curative" pacemaker. N Engl J Med 2009; 360: 88-89.

11. Constantin L, Martins JB, Fincham RW, Dagli RD. Bradycardia and syncope as manifestations of partial epilepsy. J Am Coll Cardiol 1990; 15: 900-905.

12. Connolly SJ, Sheldon R, Thorpe KE, Roberts RS, Ellenbogen KA, Wilkoff BL, et al; VPS II Investigators. Pacemaker therapy for prevention of syncope in patients with recurrent severe vasovagal syncope: Second Vasovagal Pacemaker Study (VPS II): A randomized trial. JAMA 2003; 289: 2224-2229.

13. Raviele A, Giada F, Menozzi C, Speca G, Orazi S, Gasparini G, et al; Vasovagal Syncope and Pacing Trial Investigators. A randomized, double-blind, placebo-controlled study of permanent cardiac pacing for the treatment of recurrent tilt-induced vasovagal syncope: The vasovagal syncope and pacing trial (SYNPACE). Eur Heart J 2004; 25: $1741-1748$.

14. Sumiyoshi M, Abe H, Kohno R, Sekita G, Tokano T, Nakazato Y, et al. Age-dependent clinical characteristics of micturition syncope. Circ J 2009; 73: 1651-1654.

15. Komatsu K, Sumiyoshi M, Abe H, Kohno R, Hayashi H, Sekita G, et al. Clinical characteristics of defecation syncope compared with micturition syncope. Circ J 2010; 74: 307-311. 